Copyright (C 2015 IEEE. Personal use of this material is permitted. Permission from IEEE must be obtained for all other uses, in any current or future media, including reprinting/republishing this material for advertising or promotional purposes, creating new collective works, for resale or redistribution to servers or lists, or reuse of any copyrighted component of this work in other works. 


\title{
Detection of Power Transformer Bushing Faults and Oil Degradation using Frequency Response Analysis
}

\author{
Naser Hashemnia, A. Abu-Siada and S. Islam \\ Curtin University \\ Perth, Western Australia
}

\begin{abstract}
Frequency response analysis (FRA) has been globally accepted as a reliable tool to detect mechanical deformation within power transformers. However, because of its reliance on graphical analysis, interpretation of FRA signature is still a challenging area that calls for skilled personnel, as so far, there is no widely accepted reliable standard code for FRA signature identification and quantification. While several papers investigating the impact of various mechanical winding deformations on the transformer FRA signature can be found in the literature, no attention was given to investigate the impact of various bushing faults and transformer oil degradation on the FRA signature. This paper introduces a detailed simulation and practical analyses to elaborate the impact of bushing faults as well as transformer oil degradation on the transformer FRA signature. In this regard, the physical geometrical dimension of a three phase power transformer is simulated using 3D finite element analysis to emulate the real transformer operation. Various bushing faults have been emulated on the studied model and oil degradation is implemented through changing oil permittivity. Practical FRA test is conducted on a three phase $132 \mathrm{kV}$, 35MVA power transformer to validate the simulation results. Results show that bushing faults and oil degradation can be visibly detected through FRA signature.
\end{abstract}

Index Terms - Power transformer, Condition monitoring, Transformer insulation degradation, Frequency response analysis, Bushing faults

\section{INTRODUCTION}

POWER transformers are one of the most critical and expensive assets in electrical transmission and distribution networks. The impacts of an in-service transformer failure can be catastrophic as it may cause extended outages, costly repairs and potentially serious injury or fatality. Furthermore, the continuous increase in load demand, nonlinear loads, smart appliances and plug-in electric vehicles that are considered as sizeable, unpredictable and source of harmonics loads along with the significant aged transformer population worldwide has increased the likelihood of transformer catastrophic failures [1]. Therefore, it is essential to adopt reliable diagnostic tools to precisely identify the health condition and to provide a proper maintenance action for in-service power transformers. The majority of worldwide transformers currently in service were installed prior to 1980 and as a result the bulk of the population is approaching or has already exceeded its design life [2-8]. This poses a significant risk for utilities and other power network stakeholders. Consequently, monitoring and diagnostic techniques are essential to decrease maintenance and to improve reliability of the existing power transformers [9-11]. Bushings are one of the major components causing forced outages of power transformers [12]. A CIGRE international survey [13] indicates that the most frequent sources of transformer failures are attributed to tap changers, bushings, and paper-oil insulation system which is mainly deteriorated due to heat, oxidation, acidity, and moisture. Various diagnostic techniques have been adopted for transformer bushings such as visual inspection, infrared scanning, dc insulation resistance test, capacitance and power factor $(\tan \delta)$ measurement, partial discharge, oil sampling and frequency response analysis [14-16].

Frequency Response Analysis (FRA) is considered as a reliable tool to detect various winding deformations within power transformers. While many researchers investigated the impact of various mechanical winding deformations such as axial displacement [17, 18], buckling deformation [19-21], disk space variation [22] and short circuit turns [23] on the transformer FRA signature, no attention was given to the impact of transformer insulation aging and various bushings faults on the FRA signature [20, 24, 25]. In this paper, the geometric dimensions of a three-phase transformer including detailed transformer windings, insulation system and bushings are simulated using 3D finite element modelling (FEM) that allows the extraction of equivalent electrical circuit parameters of the transformer before and after applying a physical faults to the model. In this way the impact of various faults on transformer equivalent circuit parameters and hence on its FRA signature can be investigated. The impact of transformer bushings and insulation oil degradation on transformer FRA signature is elaborated through simulation as well as practical measurement analyses.

\section{INSULATION SYSTEM PROPERTIES}

Moisture in transformer is caused due to insulation aging, atmospheric leak, cellulose decomposition and after dry-out process where moisture migration between oil and paper 
insulation takes place [26, 27]. Dissipation factor is a method to identify the moisture content inside the dielectric insulation $[2,16]$. The complex permittivity $\varepsilon_{\text {oil }}^{*}$ of transformer oil at a given frequency $w(\mathrm{rad} / \mathrm{s})$ and temperature $T$ can be calculated as [9]:

$\varepsilon_{\text {oil }}^{*}=\frac{\sigma_{\text {Oil }}(T)}{j . \varepsilon_{0} . \omega}+2.2=\varepsilon^{\prime}(\omega)-j \varepsilon^{\prime \prime}(\omega)$

where $\sigma_{\text {Oil }}$ is oil conductivity, $\varepsilon_{0}$ is the permittivity of free space.

Dielectric behavior usually refers to the variation of $\varepsilon^{\prime}$ and

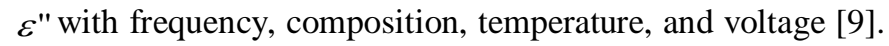
The real and imaginary parts of the dielectric permittivity as a function of the frequency are given by [28]:

$$
\begin{aligned}
& \varepsilon^{\prime}=\varepsilon_{\infty}+\frac{\varepsilon_{0}-\varepsilon_{\infty}}{1+\omega^{2} \tau^{2}} \\
& \varepsilon^{\prime \prime}=\frac{\left(\varepsilon_{0}-\varepsilon_{\infty}\right) \omega \tau}{1+\omega^{2} \tau^{2}}
\end{aligned}
$$

where $\varepsilon_{\infty}$ is the infinite-frequency dielectric constant and $\tau$ is the dielectric time constant.

For an equal thickness of oil-paper composite transformer insulation, $\tau$ is given by [14]:

$$
\tau=\frac{\varepsilon_{\text {paper }}-\varepsilon_{\text {oil }}}{\sigma_{\text {paper }}+\sigma_{\text {oil }}}
$$

where, $\varepsilon_{\text {paper }}$ and $\varepsilon_{\text {oil }}$ are the absolute values of permittivity for paper and oil insulation; $\sigma_{\text {paper }}$ and $\sigma_{\text {oil }}$ represent the conductivity of paper and oil insulation, respectively.

The computation of oil conductivity requires the transformer physical geometry details as shown in Figure 1 and dielectric permittivity of the test object [28].

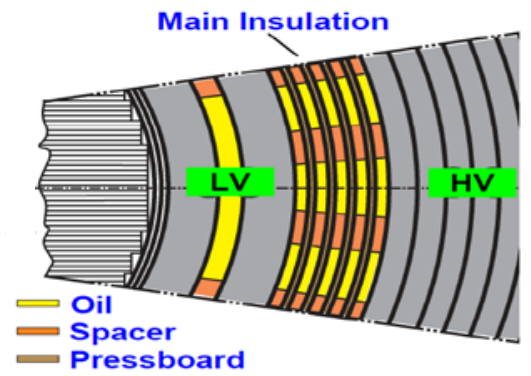

Figure 1. Insulation System within a power transformer

\section{FINITE ELEMENT ANALYSIS}

To emulate real power transformer operation, finite element modelling (FEM) is used to construct a 3D model of the threephase transformer shown in Figure 2. Parameters of the simulated transformer are given in the Appendix. The FEM can be manipulated to evaluate the impact of moisture ingress and other contaminations of the transformer bushings and oilpaper insulation system on the transformer FRA signature. Any change in the oil-paper insulation and or bushing characteristics will result in a change in the transformer equivalent circuit parameters shown in Figure 3 and hence on the corresponding FRA signature. In the transformer distributed parameters equivalent circuit shown in Figure 3, high voltage $(\mathrm{HV})$ and low voltage (LV) windings are represented by series resistance (R) and inductance (L) shunted by capacitor $\left(\mathrm{C}_{\mathrm{s}}\right)$ and conductance $\left(\mathrm{G}_{\mathrm{s}}\right)$. The capacitance between $\mathrm{HV}$ and $\mathrm{LV}$ windings $\left(\mathrm{C}_{\mathrm{HL}}\right)$ shunted by dielectric conductance $\left(\mathrm{G}_{\mathrm{HL}}\right)$ simulate the insulation between the two windings. Also, the mutual inductances (M) between relevant coils are represented. The dielectric insulation between the $\mathrm{LV}$ winding and the earthed core and that is between the $\mathrm{HV}$ winding and the earthed tank are simulated by a capacitance $\left(\mathrm{C}_{0}\right)$ and dielectric conductance $\left(\mathrm{G}_{0}\right)$. Transformer bushing equivalent circuit is represented as a Tmodel and is discussed below.

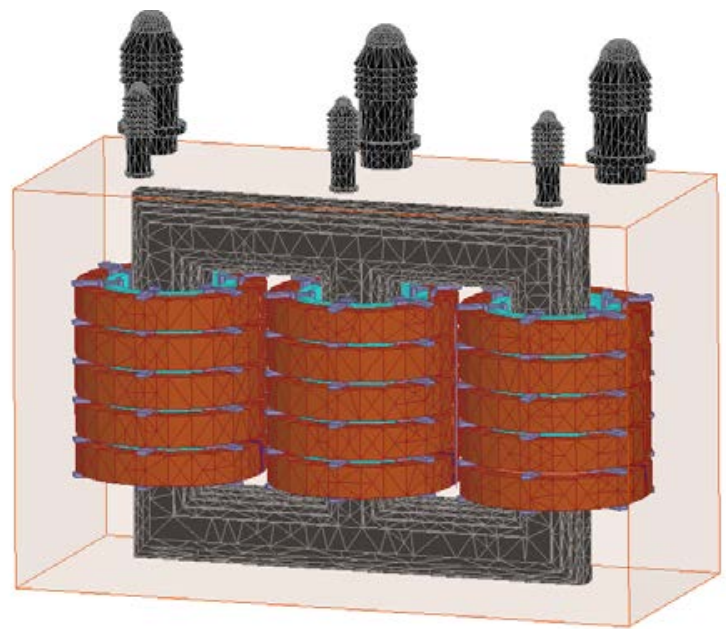

Figure 2. Three-phase 3D transformer model under investigation

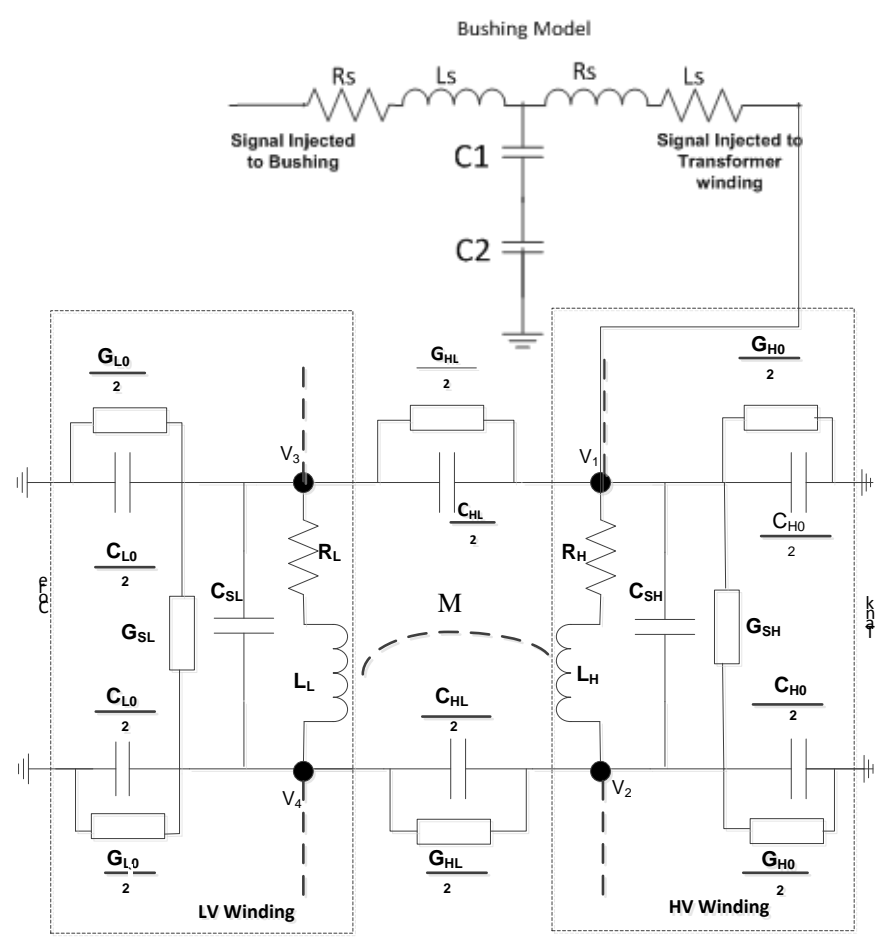

Figure 3. Transformer distributed parameters model

Capacitance and Inductance matrices including bushing equivalent circuit parameters and transformer insulation equivalent capacitance are calculated using the electric and magnetic energy density using Ansys FEM software [29]. 


\section{A. Transformer Bushing construction and equivalent circuit}

There are two common types of transformer bushings namely, solid porcelain bushing which is used for small rating transformers and oil filled condenser bushing, also known as oil impregnated paper (OIP) bushing, that is used for large rating transformers [30]. An OIP transformer bushing is composed of winding insulation paper around a central core as shown in Figure 4. The portions of bushing in air and inside the transformer are considered in the simulation. At defined intervals, conductive sheets are placed between paper layers to control the electric field distribution [31]. Layers of paper and foil are usually filled with an insulating fluid such as oil. Insulation aging and moisture content have significant effects on bushing dielectric properties.

The main insulation system is represented by capacitance $C_{1}$ in the equivalent bushing T-model shown in Figure 5 while layers near ground are represented by capacitance $\mathrm{C}_{2}$. In the bushing model shown in Figure $5, R_{s}$ and $L_{s}$ represent the central conductor within the bushing that connects the line with the transformer energised windings.

Bushings are designed to have a constant dielectric capacitance over the asset operational life [32]. Therefore, variation in bushing capacitance can be used as an indicator of a potential problem. An increase in capacitance by $3 \%$ to $5 \%$ is typically accepted as an indication of a problem within a bushing [33]. To accurately identify the effect of bushing faults on the electrical parameters of bushing equivalent $\mathrm{T}$ model, the physical geometrical dimension of a $10 \mathrm{kVA}$ bushing of the three-phase transformer shown in Figure 2 is simulated using 3D finite element software (Ansys) for healthy and faulty conditions. Faulty bushing is emulated through altering its insulation complex permittivity which is influenced by many factors such as ambient temperature and the structure of the insulation system [7].
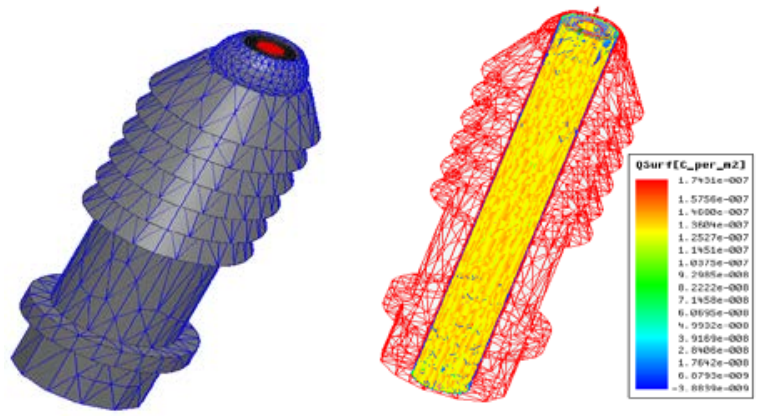

Figure 4. 3D model of Bushing solved in electrostatic FEM solver

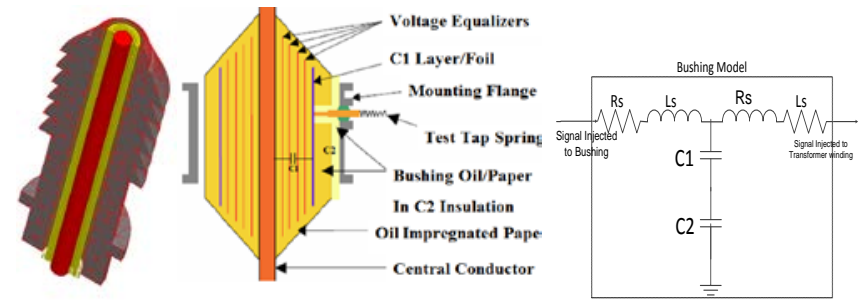

Figure 5. Transformer Bushing layers and its equivalent T-model

The electrical parameters for normal and faulty conditions are extracted using FEM based on the following three steps:

Step 1: The Transformer 3D model shown in Figure 2 is analyzed using electrostatic, magnetostatic and dc conduction solvers to obtain the capacitance, conductance and inductance matrices for healthy condition. To extract the bushing equivalent T- model parameters, effect of capacitive grading on the electric field distribution is also analysed.

Step 2: Faulty condition is simulated by changing the permittivity of the transformer oil-paper insulation of the bushing and the corresponding variations in the capacitance and inductance matrices for different faulty condition levels are calculated using the electrostatic, magnetostatic and dc conduction solvers.

Step 3: The FRA signature is plotted as the winding transfer function $\mathrm{TF}_{\mathrm{dB}}=20 \log _{10}\left|\mathrm{~V}_{0} / \mathrm{V}_{\mathrm{in}}\right|$ for healthy and faulty conditions.

Moisture content inside the bushing leads to variations of the bushing capacitive components, $\mathrm{C}_{1}$ and $\mathrm{C}_{2}$. In FEA, this effect can be simulated through changing the permittivity and/or conductivity of the dielectric insulation. In the transformer model under study, moisture content within bushing insulation is varied through increasing the oil-paper permittivity from $1 \%$ to $5 \%$. Figure 6 shows the corresponding percentage change in the bushing capacitances $C_{1}$ and $C_{2}$ due to variation in the permittivity of the bushing dielectric insulation. These results reveal that the variation of $C_{1}$ is more pronounced than $\mathrm{C}_{2}$ for the same percentage increase in dielectric permittivity, e.g. a $2 \%$ increase permittivity leads to $7.5 \%$ increase in $C_{1}$ whereas the value of $C_{2}$ increases by only $3 \%$.

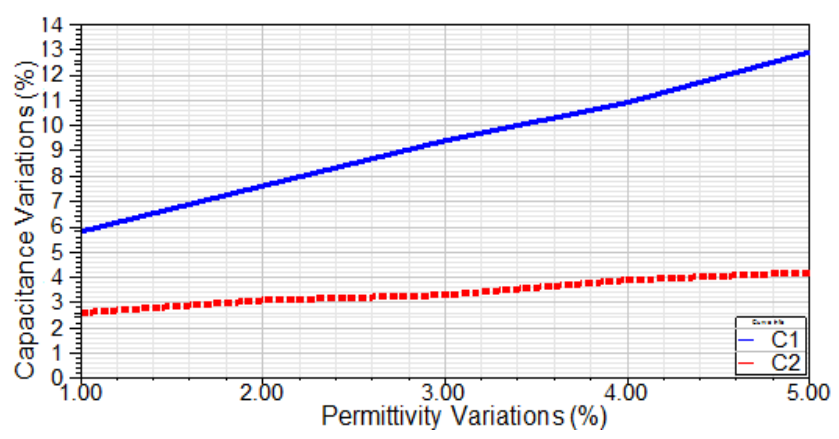

Figure 6. Capacitance variation of bushing T-model due to permittivity variation

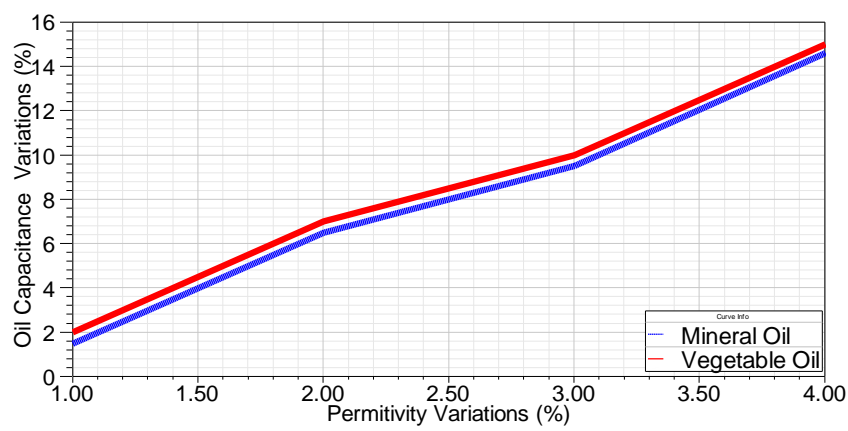

Figure 7. Variation of transformer oil effective capacitance due to permittivity variation

Figure 7 shows the impact of increasing the permittivity of transformer dielectric insulation on the variation of the total transformer oil capacitance. The figure shows that oil effective capacitance is increasing with the increase of permittivity in the two types of oil used in the simulation (vegetable and mineral). The increment in vegetable oil capacitance is 
however slightly more than that of mineral oil for the same permittivity variation. It is worth mentioning that, these calculations are conducted based on the assumption that the operating temperatures as well as the network frequency are kept constants. Simulation of moisture ingress within transformer oil through increasing oil permittivity is based on the fact that moisture content decreases the dielectric strength of the insulation oil which is corresponding to a decrease in its capacitive reactance $(1 / w c)$. As the operating frequency is maintained at the power frequency, decrement in capacitive reactance is corresponding to increment in the oil capacitance which could be simulated through the increase in oil permittivity as shown in Figures 6 and 7. It should be also noted that, there is no precise mathematical correlation between the level of moisture content in transformer oil and its dielectric permittivity developed yet. Some experimental results are presented in section 5 to investigate this correlation.

Variation of oil conductivity can be calculated using the dc conduction solver provided by Ansys software as below:

$J(x, y)=\sigma E(x, y)=-\sigma \nabla \phi(x, y)$

where, $J$ is the current density, $E$ is the electric filed intensity, $\sigma$ is the conductivity of the material (s/m) and $\phi$ is the electric potential.

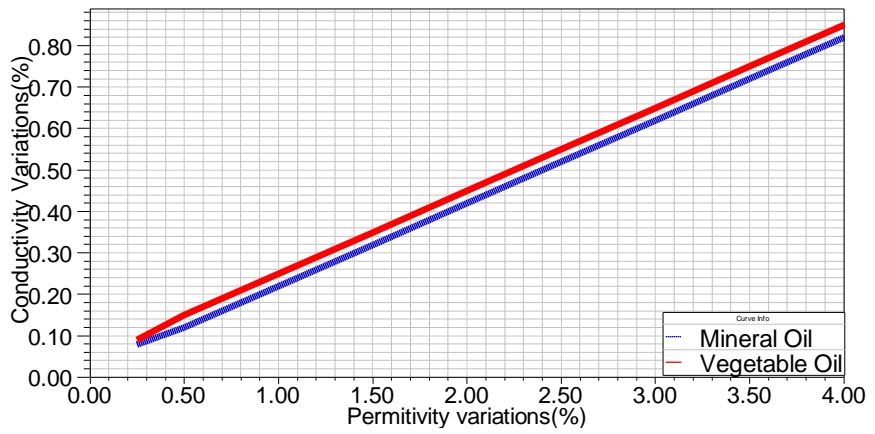

Figure 8. Variation of oil conductivity due to permittivity variation

Figure 8 shows the percentage change in vegetable and mineral oils conductivities due to the increase in dielectric oil permittivity. Figure 8 reveals that the increase in oil permittivity increases its conductivity. Simulation results also show that vegetable oil dielectric strength is slightly more sensitive to the change in oil permittivity than mineral oil as can be seen in Figures 7 and 8 .

\section{IMPACT OF BUSHING FAULT AND INSULATION DEGRADATION ON FRA SIGNATURE}

To show the impact of bushing model on the HV winding FRA signature, Figure 9 is plotted for the transformer model shown in Figure 3 with and without the inclusion of the bushing T-model. As shown in Figure 9, with the inclusion of bushing T-model, the transfer function of the HV winding develops new resonant peaks after $700 \mathrm{kHz}$ with a slight change in the magnitude. On the other hand, the magnitude and the resonant peaks do not change from the low to mid frequency range. This simulation result is confirmed by a practical FRA measurement that will be presented in the next section. This reveals that, for accurate simulation of transformer FRA signatures, bushing model should be included in the transformer high frequency equivalent circuit model. The following case studies are conducted using FEA along with the transformer distributed parameters-based equivalent model shown in Figure 3 with the inclusion of the bushing T-model shown in Figure 5.

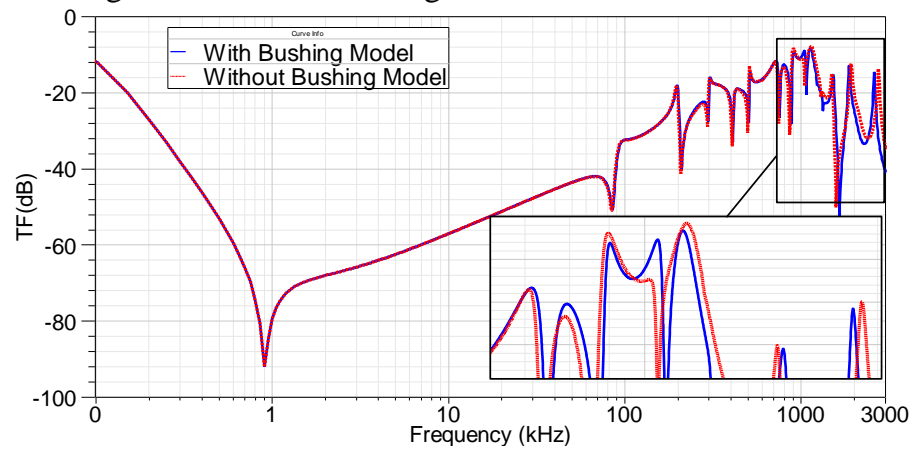

Figure 9. FRA signature of the transformer distributed model shown in Fig. 3 with and without the inclusion of bushing T-model

\section{Case study 1 (bushing insulation degradation)}

Figure 10 shows the variation of the HV FRA signature for $2 \%$ and $4 \%$ increment in the permittivity of the oil and paper within the transformer bushing. The figure shows that impact of moisture in oil on the FRA signature appears in the frequency range above $700 \mathrm{kHz}$ where the resonance and antiresonance frequencies decrease with respect to the healthy signature. The impact is more pronounced for more moisture content, which is simulated by more change in oil permittivity, within the oil.

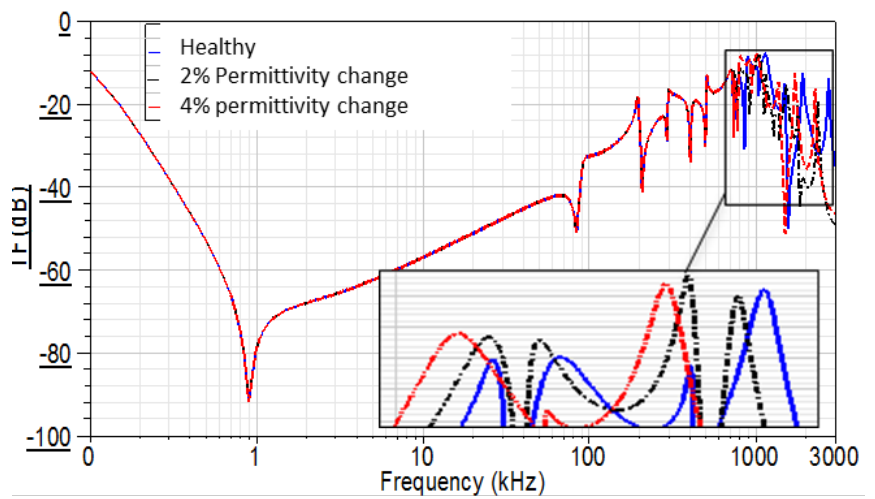

Figure 10. Effect of moisture content in bushing insulation on $\mathrm{HV}$ winding FRA signature

\section{Case study 2 (Transformer oil degradation)}

In order to exactly simulate the transformer oil degradation utilizing transformer distributed parameter model, it is essential to detect the percentage change in the electrical circuit parameters that is corresponding to a particular oil degradation level.

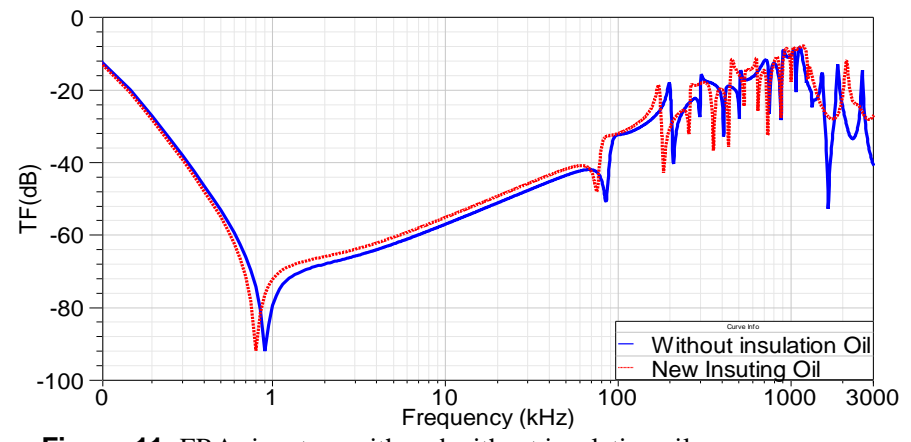

Figure 11. FRA signature with and without insulating oil 


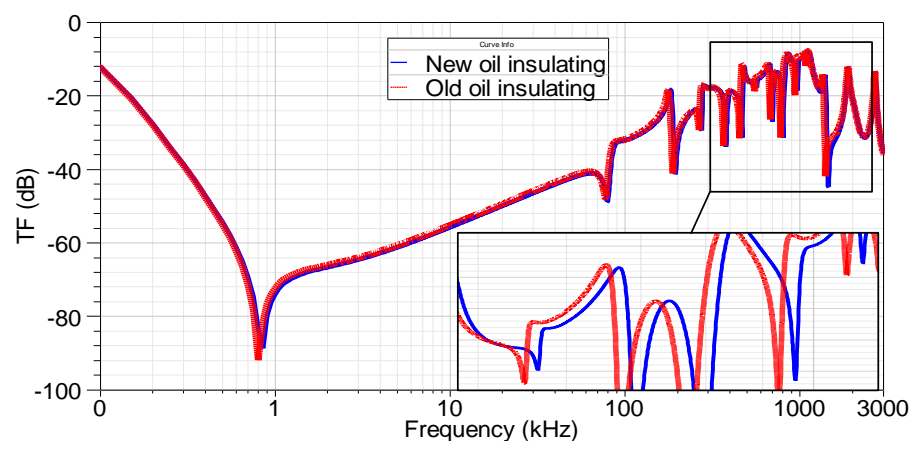

Figure 12. Impact of oil degradation on transformer FRA signature .

Figure 11 shows the effect of new insulation oil on the transformer FRA signature when compared with the oil free transformer FRA signature. As can be seen in Figure 11, new insulating oil will shift the resonance peaks to the left on the entire frequency range with respect to the FRA signature of the transformer without any insulation oil. This is attributed to the fact that adding insulation oil will increase the overall capacitance and hence reducing the resonance frequencies.

The permittivity of the new oil is increased by $4 \%$ to simulate moisture contents in the oil. As shown in Figure 12, oil degradation has a slight impact on the FRA signature at the high frequency range.

\section{Case study 3 (Disk space variation)}

To show the impact of the inclusion of the proposed bushing T-model in the transformer equivalent circuit, a disk space variation (DSV) fault is simulated on phase $\mathrm{C}$ of the $\mathrm{HV}$ winding as shown in Figure 13. Finite element calculations reveal that due to DSV, the shunt capacitance at the location of the fault and some elements associated to the inductance matrix will change significantly [11]. Figure 14 and Table 1 show the variation of the resonant peaks with and without the bushing T-model connected to the transformer model shown in Fig. 3. Figure 14 and Table 1 reveal that the variation of the resonant peaks due to DSV starts after $300 \mathrm{kHz}$ and there is a considerable change in resonant peaks when the proposed busing T-model is included. This is attributed to the high capacitive component added to the transformer model when bushing model is considered.

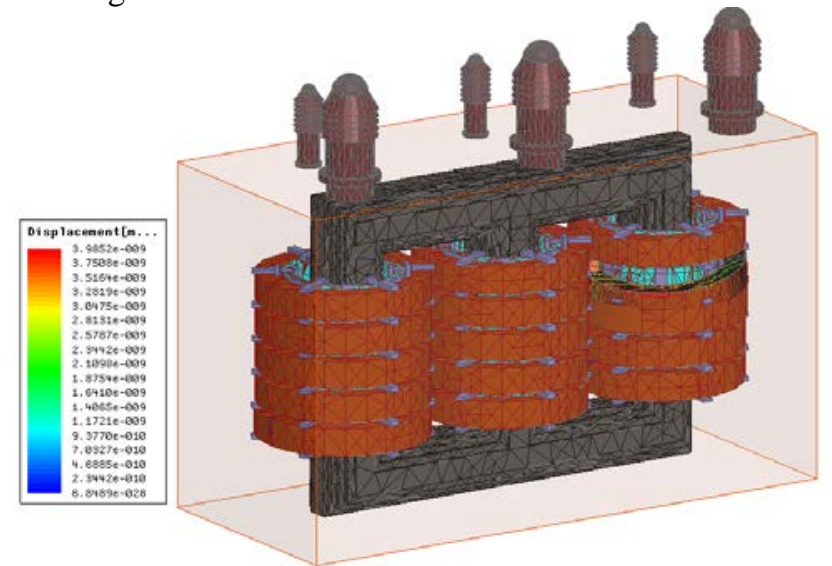

Figure 13. Disk space variation fault on Phase C

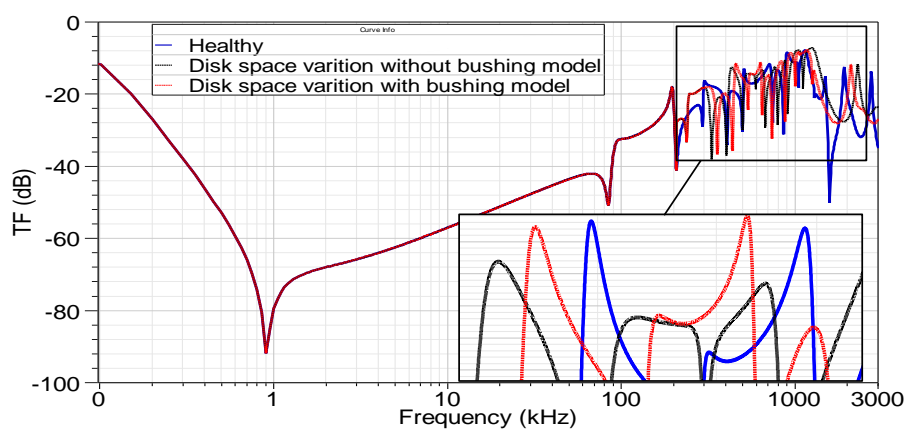

Figure 14. Impact of DSV on FRA signature with and without bushing model

Table 1. Change in resonance frequencies due to DSV fault

\begin{tabular}{|c|c|c|}
\hline \multirow{2}{*}{$\begin{array}{l}\text { Resonance Frequencies (Normal Condition; } \\
\qquad \mathrm{kHz})\end{array}$} & \multicolumn{2}{|c|}{$\Delta \mathrm{f} F R A$ signature; $\mathrm{kHz}$} \\
\hline & $\begin{array}{l}\text { Without } \\
\text { Bushing }\end{array}$ & $\begin{array}{c}\text { With } \\
\text { Bushing }\end{array}$ \\
\hline 330 & +1.2 & +1.6 \\
\hline 380 & +2.3 & +2.8 \\
\hline 752 & -6.8 & -7.6 \\
\hline 986 & -26.6 & -31.6 \\
\hline 1232 & -32.5 & -43.6 \\
\hline 1745 & -40.6 & -56.2 \\
\hline 2890 & -69.3 & -78.3 \\
\hline
\end{tabular}

\section{EXPERIMENTAL RESULTS}

As stated in the simulation results, there is no specific mathematical correlation between moisture concentration in transformer oil and its dielectric permittivity. This is attributed to the fact that moisture distribution within transformer insulation is not static due to water migration between solid insulation and oil that mainly depends on insulation temperature. Cellulosic insulation is highly hydrophilic and it contains most of the transformer water (about 1 to $5 \%$ in weight), whereas oil is less hydrophobic and normally contains a few parts per million of water [34, 35]. Figure 15 shows some practical measurements for the percentage change in oil permittivity and the corresponding moisture content in transformer oil conducted on various power transformers for 5 years [36]. Other parameters such as oil resistivity and dissipation factor are included in Table A.5 in the Appendix. The obtained results show that moisture content in transformer oil significantly affects oil relative permittivity (Er).

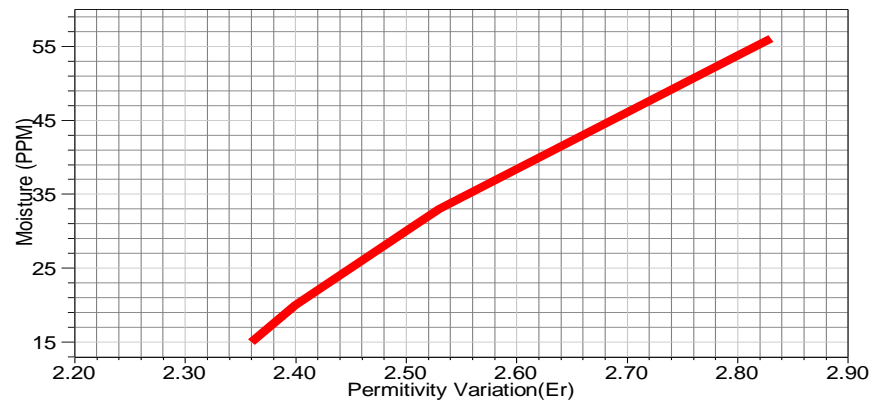

Figure 15 Measurement of moisture variation versus Permittivity variation

To assess the accuracy of the proposed bushing model, the obtained simulation results shown above are compared with practical FRA signature that is conducted on a three phase $132 \mathrm{kV}, 35 \mathrm{MVA}$ power transformer at ambient temperature 25 ${ }^{\circ} \mathrm{C}$. The FRA signature for phase $\mathrm{A}$ with and without the bushing is obtained using frequency response analyser as shown in Figure 16 which reveals the impact of the bushing on 
the transformer FRA signature in the high frequency range. This confirms the simulation results of Figure 9.

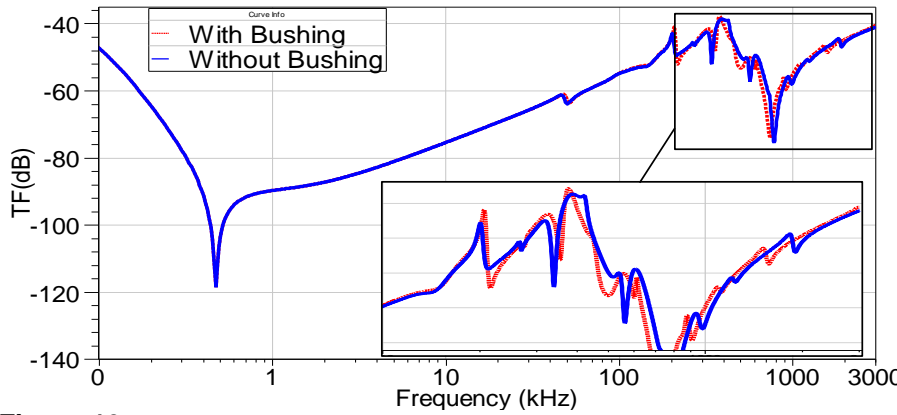

Figure 16. Practical phase-A FRA signature with and without bushing

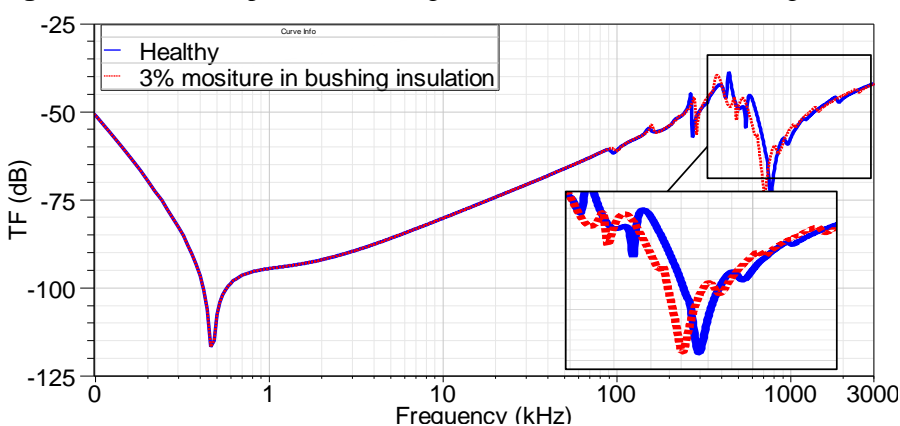

Figure 17. Practical phase-A FRA signature with new oil and with $3 \%$ moisture content in the bushing oil

The transformer bushing oil is tested and 3\% moisture content is found in the HV bushing of Phase-A. FRA measurement is conducted on this phase and compared with the FRA signature of the same phase with new oil. As shown in Figure 17, resonant peaks in the high frequency range above $700 \mathrm{kHz}$ are shifted to the left due to the existence of moisture in bushing insulating oil. This confirms the FEM simulation results shown in Figure 10.

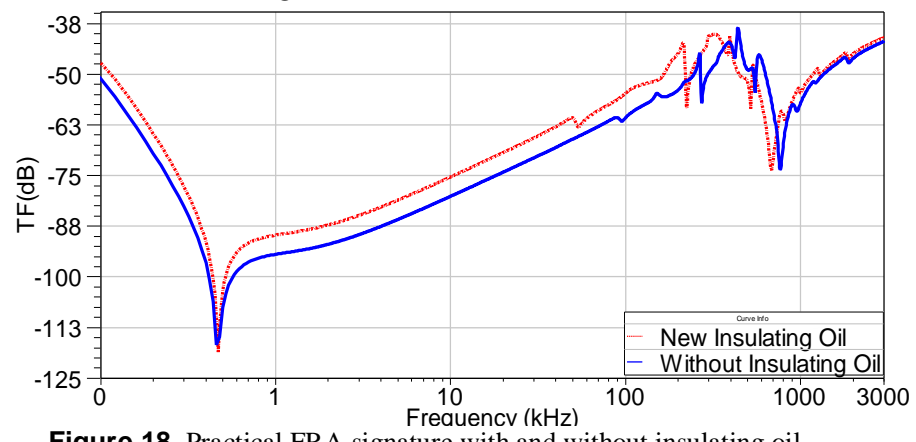

Figure 18. Practical FRA signature with and without insulating oil

To investigate the impact of insulating oil on the FRA signature, FRA measurement is conducted on Phase A of the transformer $\mathrm{HV}$ windings with and without new insulating oil as shown in Figure 18. The FRA measured signature reveals that the signature shifts to the left on the entire frequency range due to the change of the capacitance matrix elements. This is similar to the simulation results obtained in Figure 11 and the practical test presented in [28].

\section{CONCLUSION}

This paper presents detailed simulation and practical analyses to assess the impact of bushing and insulation oil health condition on the transformer FRA signature. In contrary with other papers that investigated the transformer FRA signature using a high frequency transformer model without considering bushing model, results of this paper shows that bushing model should be considered in the transformer linear model for accurate FRA simulation. Bushing model increases the capacitive components of the power transformer and consequently, its impact is more pronounced in the high frequency range. Simulation and practical results also show that moisture within the insulating oil of transformer bushing can be detected in the high frequency range of the transformer FRA signature as it alters the resonance frequencies location and magnitude in this frequency range. The paper also introduces effective charts for the correlation between transformer oil permittivity and oil capacitance and conductivity. These charts will aid in further studies about the development of a precise correlation between moisture content in transformer oil and its dielectric permittivity.

\section{Acknowledgment}

Authors would like to thank TxMonitor Company in Perth, Western Australia, for providing the practical measurements of Figure 15 and Table A.5.

\section{Appendix}

Table A.1. Dielectric properties of different oils

\begin{tabular}{c|cc}
\hline Dielectric properties & Vegetable Oil & Mineral Oil \\
\hline$\varepsilon$ & 3.4 & 2.4 \\
$\mathrm{q}$ & $3 * 10^{-11}$ & $9 * 10^{-12}$ \\
\hline
\end{tabular}

Table A.2. Dielectric properties of bushing

\begin{tabular}{l|lll}
\hline Dielectric properties & Oil & Paper layer & porcelain \\
\hline
\end{tabular}

\begin{tabular}{|c|c|}
\hline \multicolumn{2}{|c|}{ Table A.3. Transformer Parameters } \\
\hline Description & Value \\
\hline HV/LV Rating & $11 \mathrm{kV} / 433 \mathrm{~V}$ \\
\hline $\mathrm{Z} \%$ & 9.49 \\
\hline HV Terminal Resistance & $0.915 \Omega$ \\
\hline HV Inductance & $101 \mathrm{mH}$ \\
\hline LV Inductance & $20 \mu \mathrm{H}$ \\
\hline HV-LV Cap & $75 \mathrm{pF}$ \\
\hline LV-Core Cap & $63 \mathrm{pF}$ \\
\hline HV-Tank Cap & $11 \mathrm{pF}$ \\
\hline
\end{tabular}

Table A.4. Bushing Model Parameters (T Model)

\begin{tabular}{c|cccc}
\hline Electrical parameters & $C 1$ & $C 2$ & $L_{S}$ & $R_{S}$ \\
\hline Value & $2000 \mathrm{pF}$ & $450 \mathrm{pF}$ & $2.5 \mu \mathrm{H}$ & $0.2 \Omega$ \\
\hline
\end{tabular}

Table A.5 Some practical Measurement[36]

\begin{tabular}{|c|c|c|c|c|}
\hline 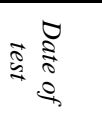 & 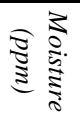 & 胥 & 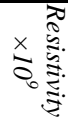 & $\begin{array}{l}\tilde{T} \\
\text { Oे } \\
0\end{array}$ \\
\hline Jan-11 & 34 & 2.61 & 52.3 & 0.41 \\
\hline Feb-12 & 42 & 2.72 & 52.1 & 0.36 \\
\hline Oct-12 & 53.71 & 2.8 & 53.3 & 0.42 \\
\hline Oct-12 & 31 & 2.51 & 58.3 & 0.39 \\
\hline Nov-14 & 7.93 & 2.32 & 66.1 & 0.18 \\
\hline Nov-14 & 10.97 & 2.36 & 64.3 & 0.32 \\
\hline Dec-14 & 12 & 2.4 & 63.1 & 0.36 \\
\hline Apr-15 & 33 & 2.53 & 55.3 & 0.40 \\
\hline Apr-15 & 56 & 2.83 & 53.3 & 0.41 \\
\hline
\end{tabular}

\section{REFERENCES}

[1] A. S. Masoum, S. Deilami, P. S. Moses, M. A. S. Masoum, and A. AbuSiada, "Smart load management of plug-in electric vehicles in distribution and residential networks with charging stations for peak shaving and loss minimisation considering voltage regulation," Generation, Transmission \& Distribution, IET, vol. 5, pp. 877-888, 2011. 
[2] A. Mikulecky and Z. Stih, "Influence of temperature, moisture content and ageing on oil impregnated paper bushings insulation," Dielectrics and Electrical Insulation, IEEE Transactions on, vol. 20, pp. 1421-1427, 2013.

[3] "The short-circuit strength of the inner windings of transformers against radial forces," CIGRE, Paris, France,1962.

[4] A. Abu-Siada and S. Islam, "A new approach to identify power transformer criticality and asset management decision based on dissolved gas-in-oil analysis," Dielectrics and Electrical Insulation, IEEE Transactions on, vol. 19, pp. 1007-1012, 2012.

[5] L. Sin Pin, A. Abu-Siada, and S. Islam, "Furan measurement in transformer oil by UV-Vis spectral response using Fuzzy Logic," in Electrical and Computer Engineering, 2008. ICECE 2008. International Conference on, 2008, pp. 716-720.

[6] K. G. N. B. Abeywickrama, Y. V. Serdyuk, and S. M. Gubanski, "Exploring possibilities for characterization of power transformer insulation by frequency response analysis (FRA)," Power Delivery, IEEE Transactions on, vol. 21, pp. 1375-1382, 2006.

[7] N. Abeywickrama, Y. V. Serdyuk, and S. M. Gubanski, "HighFrequency Modeling of Power Transformers for Use in Frequency Response Analysis (FRA)," Power Delivery, IEEE Transactions on, vol. 23, pp. 2042-2049, 2008.

[8] N. Abeywickrama, Y. V. Serdyuk, and S. M. Gubanski, "Effect of Core Magnetization on Frequency Response Analysis (FRA) of Power Transformers," Power Delivery, IEEE Transactions on, vol. 23, pp. 1432-1438, 2008.

[9] A. Hyun-Mo, L. Ji-Yeon, K. Joong-Kyoung, O. Yeon-Ho, J. Sang-Yong, and H. Sung-Chin, "Finite-Element Analysis of Short-Circuit Electromagnetic Force in Power Transformer," Industry Applications, IEEE Transactions on, vol. 47, pp. 1267-1272, 2011.

[10] M. Bigdeli, M. Vakilian, E. Rahimpour, and D. Azizian, "Transformer winding diagnosis using comparison of transfer function coefficients," in Electrical Engineering/Electronics, Computer, Telecommunications and Information Technology (ECTI-CON), 2011 8th International Conference on, 2011, pp. 681-683.

[11] A. Abu-Siada, N. Hashemnia, S. Islam, and M. A. S. Masoum, "Understanding power transformer frequency response analysis signatures," Electrical Insulation Magazine, IEEE, vol. 29, pp. 48-56, 2013.

[12] R. Nikjoo and H. Edin, "Effect of transformer winding on the transient response of power transformer bushings," in Lightning Protection (ICLP), 2012 International Conference on, 2012, pp. 1-5.

[13] P. B. S. M. Gubanski, G. Csepes, V. Der Houhanessian, J. Filippini, P., U. G. Guuinic, V. Karius, J. Lapworth, G. Urbani, P. Werelius and, and W. Zaengl, "Dielectric Response Methods for Diagnostics of PowerTransformers," vol. 254, ed. Paris: CIGRE Technical Brochure, 2004.

[14] J. A. Almendros-Ibaez, J. C. Burgos, and B. Garcia, "Transformer Field Drying Procedures: A Theoretical Analysis," Power Delivery, IEEE Transactions on, vol. 24, pp. 1978-1986, 2009.

[15] C. Ekanayake, S. M. Gubanski, A. Graczkowski, and K. Walczak, "Frequency response of oil impregnated pressboard and paper samples for estimating moisture in transformer insulation," Power Delivery, IEEE Transactions on, vol. 21, pp. 1309-1317, 2006.

[16] Y. Du, M. Zahn, B. C. Lesieutre, A. V. Mamishev, and S. R. Lindgren, "Moisture equilibrium in transformer paper-oil systems," Electrical Insulation Magazine, IEEE, vol. 15, pp. 11-20, 1999.

[17] E. Rahimpour, J. Christian, K. Feser, and H. Mohseni, "Transfer function method to diagnose axial displacement and radial deformation of transformer windings," Power Delivery, IEEE Transactions on, vol. 18, pp. 493-505, 2003.

[18] N. Hashemnia, A. Abu-Siada, and S. Islam, "Improved power transformer winding fault detection using FRA diagnostics ??? part 1: axial displacement simulation," Dielectrics and Electrical Insulation, IEEE Transactions on, vol. 22, pp. 556-563, 2015.

[19] M. Bagheri, M. S. Naderi, and T. Blackburn, "Advanced transformer winding deformation diagnosis: moving from off-line to on-line," Dielectrics and Electrical Insulation, IEEE Transactions on, vol. 19, pp. 1860-1870, 2012.

[20] C. A2.26, "Mechanical Condition Assessment of Transformer Windings Using Frequency Response Analysis (FRA)," CIGRE Brochure 342April 2008.

[21] N. Hashemnia, A. Abu-Siada, and S. Islam, "Improved power transformer winding fault detection using FRA diagnostics ??? part 2: radial deformation simulation," Dielectrics and Electrical Insulation, IEEE Transactions on, vol. 22, pp. 564-570, 2015.

[22] K. Pourhossein, G. B. Gharehpetian, and E. Rahimpour, "Buckling severity diagnosis in power transformer windings using Euclidean Distance classifier," in Electrical Engineering (ICEE), 2011 19th Iranian Conference on, 2011, pp. 1-1.

[23] S. Liu, Z. Liu, and O. A. Mohammed, "FE-Based Modeling of SinglePhase Distribution Transformers With Winding Short Circuit Faults," Magnetics, IEEE Transactions on, vol. 43, pp. 1841-1844, 2007.

[24] "IEEE Guide for the Application and Interpretation of Frequency Response Analysis for Oil-Immersed Transformers," IEEE Std C57.1492012, pp. 1-72, 2013.

[25] IEC, "Power transformers -Part 18: Measurement of frequency response," ed: International Electrotechnical Commission, Ed.1 2012, p. 90.

[26] F. Meghnefi, I. Fofana, H. Hemmatjou, and M. Farzaneh, "Deriving an equivalent circuit of composite oil paper insulation for understanding the Frequency Domain Spectroscopic measurements," in Electrical Insulation and Dielectric Phenomena, 2009. CEIDP '09. IEEE Conference on, 2009, pp. 478-481.

[27] A. Setayeshmehr, I. Fofana, C. Eichler, A. Akbari, H. Borsi, and E. Gockenbach, "Dielectric spectroscopic measurements on transformer oilpaper insulation under controlled laboratory conditions," Dielectrics and Electrical Insulation, IEEE Transactions on, vol. 15, pp. 1100-1111, 2008.

[28] M. Bagheri, B. T. Phung, and T. Blackburn, "Influence of temperature and moisture content on frequency response analysis of transformer winding," Dielectrics and Electrical Insulation, IEEE Transactions on, vol. 21, pp. 1393-1404, 2014.

[29] ANSYS help [Online].

[30] Z. Daxiong, "An improved method of measuring $\mathrm{C}<$ sub $>1</$ sub $>$ power factor of resistance-graded bushings," Power Delivery, IEEE Transactions on, vol. 14, pp. 437-442, 1999.

[31] M. Melo, M. E. G. Alves, and G. A. Moura, "Experience with on-line monitoring of capacitance and tangent delta of condensive bushings," in Transmission and Distribution Conference and Exposition: Latin America, 2008 IEEE/PES, 2008, pp. 1-6.

[32] M. B. Goff and A. H. Eltom, "Oil filled bushing secrets revealed," in Industry Applications Society Annual Meeting, 2013 IEEE, 2013, pp. 19.

[33] P. Hua-Dong, D. Ming, R. Ming, M. Jin, and Z. Zhi, "Insulation diagnosis for $220 \mathrm{kV}$ oil-immersed current transformer by frequency dielectric spectroscopy," in Electrical Insulation Conference (EIC), 2011, 2011, pp. 69-73.

[34] M. Koch and T. Prevost, "Analysis of dielectric response measurements for condition assessment of oil-paper transformer insulation," Dielectrics and Electrical Insulation, IEEE Transactions on, vol. 19, pp. 1908-1915, 2012.

[35] B. García, D. García, and G. Robles, "Development of a Moisture-inSolid-Insulation Sensor for Power Transformers," Sensors (Basel, Switzerland), vol. 15, pp. 3610-3624, 02/04

[36] "TxMonitor Consulatant condition monitoring and asset managment of Power Transformers " http://www.txmonitor.com/ 